\title{
BRUJAS, COQUETAS Y CIUDADANAS: LA ESCRITURA DE ALECIA MARCIANO CONTRA LA HISTORIA
}

\author{
Mariana Libertad Suárez
}

\begin{abstract}
RESUMEN
Partiendo de la revisión de las propuestas de Lola Luna (1996) en torno a la dificultad y/o necesidad para pensar el pasado desde la experiencia femenina, se pretende estudiar la novela Bruja del Ávila (1957), de la escritora venezolana Alecia Marciano. Ello permitirá hurgar en el territorio de enunciación de la autora dentro del campo cultural del país, el gesto autoescritural que acompaña la revisión de la Historia contenida en sus ficciones y la ruptura que ocasiona su escritura con/en los discursos fundacionales gestadores del proyecto desarrollista de nación.

Palabras clave: Alecia Marciano, contrahistoria, sujeto femenino, perezjimenismo, autoescritura.
\end{abstract}

\begin{abstract}
In the book Leyendo como mujer la imagen de la mujer (1996), Lola Luna proposes that it is necessary to reconstruct the past, taking into account women's experience. These foundations allow us to understand the novel Bruja del Ávila (1957), by Venezuelan writer Alecia Marciano. With this reading we delve into the position of the writer in the cultural field, how she writes herself into the national history, and how she breaks the stories that created the idea of development.
\end{abstract}

Key words: Alecia Marciano, anti-history, female subject, selfwriting.

\section{El pasado en femenino}

La estrategia de "separar" la historia de las mujeres ha contribuido en un primer momento a focalizar el estudio sobre un sujeto específico. Un sujeto marcado por un "silencio" cultural, enmascarado por una amplia producción sobre las mujeres que ha sustituido a sus voces. El silencio del que pretendemos rescatar a nuestras escritoras es la característica cultural de un grupo muted, un grupo antropológicamente silenciado [...] La esfera de poder público donde se ubica la "autoridad" parece ser la zona del silencio femenino, a modo de voces eliminadas de los discursos que representan y simbolizan el poder y eliminadas, por tanto, de una historia atenta principalmente a los hechos de poder-político para la construcción de la hipótesis histórica. Incluso en la revisión que suponen las investigaciones sobre minorías y grupos marginados, las mujeres no han solido ser consideradas como tales. Y, al igual que la historiografía marxista no ha tenido en cuenta que la experiencia de clase varía según el sexo, hasta muy recientemente el componente genérico no ha sido considerado como categoría de análisis histórico (Lola Luna 1996: 70-71).

Dra. Mariana Libertad Suárez. Profesora titular del Departamento de Lengua y Literatura; Coordinadora de Publicaciones. Universidad Simón Bolívar, Venezuela.

Correo electrónico: marisuarez@usb.ve

Recepción: 03- 05- 2011

Aceptación: 18- 07- 2011 
Estos comentarios expuestos por Lola Luna en su libro Leyendo como mujer la imagen de la mujer (1996) constituyen un punto de partida útil para comprender cierta tendencia de ciertas autoras venezolanas de los años cincuenta a reescribir en sus ficciones un pasado alternativo. Obras como Otoniel (1950), de Inés Guzmán Arias; Memorias de una loca (1955), de Conny Méndez; Memorias disparatadas (1959), de Cristina Ferrero; o La mujer del caudillo (1952), de Nery Russo, se erigen como ejemplos claros de una búsqueda genealógica propia de ciertas identidades que -como es el caso de las intelectuales venezolanas del siglo XX- acababan de adquirir alguna visibilidad en el campo cultural.

Según Luna, pocas veces la ciencia histórica ha dado cabida -tanto menos en el segundo tercio del siglo XX- a la mujer como subjetividad y/o a la experiencia femenina. Quizás por encontrarse al margen de los espacios tradicionalmente asignados al poder, las mujeres han carecido de "registros oficiales" en la interpretación de la Historia. Del mismo modo, la autora señala que hay una necesidad de "discursivizar", es decir, de proporcionarle narrativa e identidad, a un grupo determinado de mujeres, de cuya existencia sólo se tiene noticias "al margen" de los manuales o textos divulgativos.

Ante ello, cabría preguntarse si las expresiones periféricas aludidas por Luna no estarían cumpliendo una función semejante a la de la historiografía, es decir, si -más allá de su poca difusión- estos registros no estarían institucionalizando, fijando y cargando de discurso a un grupo de subjetividades en "muted". La amplitud de las respuestas posibles provoca otras inquietudes: ¿es necesaria la representación de la experiencia femenina en un marco de conocimiento legitimado como "veraz"?, ¿por qué esta ensayista propone como una búsqueda indispensable la apertura de las Ciencias Sociales y no se esfuerza en legitimar los registros ya existentes?, ¿por qué las huellas autoescriturales no son documentos igualmente válidos, según su perspectiva, en la reorganización del pasado?

Precisamente aquí se replantea la interrogante acerca de si es posible seguir hablando de Historia cuando se han modificado todos los elementos constitutivos del orden del discurso ${ }^{1}$, es decir, cuando el ejercicio de rememoración y ordenamiento no se ha llevado a cabo ni por el mismo sujeto - pues ahora se trata de mujeres con una identidad inestable-, ni en las mismas circunstancias -dado que el lenguaje ha ido perdiendo su tono analítico-, ni en torno a los mismos objetos enunciados -como los enfrentamientos bélicos, las sucesiones en el poder o los levantamientos populares- que solía emplear la ciencia histórica. Al respecto, Joan Scott propone:

\footnotetext{
Nos damos cuenta -escribieron tres historiadoras feministas- de que la inclusión de las mujeres en la historia implica necesariamente la redefinición y ampliación de nociones tradicionales del significado histórico, de modo que abarque la experiencia personal y subjetiva lo mismo que las actividades públicas y políticas. No es demasiado sugerir que, por muy titubeantes que sean los comienzos reales, una metodología como ésta implica no sólo una nueva historia de las mujeres, sino también una nueva historia. La forma en que esta nueva historia debería incluir y dar cuenta de la experiencia de las mujeres debería depender de la amplitud con que pudiera desarrollarse el género como categoría de análisis. (Scott 1996: 267- 268)
}

En esta afirmación de Joan W. Scott, contenida en su artículo "El género²: una categoría útil para el análisis histórico" (1996), se rearticulan buena parte de los problemas fundamentales comentados en los párrafos anteriores: la relación conflictiva entre el sujeto femenino y la historiografía tradicional, el uso de la categoría de género como un significante que acolcha ${ }^{3}-\mathrm{o}$, al menos, podría acolchar- el contenido de la Historia y, por último, la insuficiencia de la disciplina científicosocial para dar cuenta de estas movilizaciones. $\mathrm{O}$, lo que es lo mismo, esta estudiosa acusa - a partir de la década de los ochenta, del siglo XX- la 
demanda de un método alternativo para el análisis y, sobre todo, para la gestación de esta historia descentrada que contempla las voces, los cuerpos y las acciones femeninas en su proceso de revisión.

Pese a ello, existe una dificultad dentro de la propuesta que impide su naturalización aún entre las estudiosas del género y que está asociada a la vieja disputa existente entre el feminismo de la igualdad y el de la diferencia. Si, como propone Zizek en su texto El sublime objeto de la ideología (2001), la presencia de un significante acolchador genera la ilusión de que determinadas categorías de análisis siempre contuvieron un significado oculto y, lo que resulta aún más interesante, que este se devela como "original" ante el nuevo punto de convergencia o "point de caption", la sugerencia de Scott debía conducirnos a pensar que "la verdadera Historia" es aquella que incluye la participación femenina y que diluye los límites entre las labores cotidianas y el quehacer político.

Surgen entonces una serie de dudas sobre hacia dónde esta autora dirige sus comentarios ¿Hacia la reivindicación de las actividades domésticas como prácticas que incidieron directamente en la vida pública o hacia la recuperación de los sujetos femeninos que -pese a haber participado en actividades económicas y políticas- son obviados dentro de los ejercicios de sistematización del pasado?, ¿hacia la reivindicación de la memoria individual como forma de conocimiento de cierta antigüedad colectiva o hacia la inscripción del sujeto femenino en el discurso de la historiografía tradicional? A partir de esta disputa se sugiere leer la novela Bruja del Ávila, de Alecia Marciano: una vía alternativa que si bien no consigue penetrar el espacio del saber positivista, sí logra movilizar algunos significantes asociados a la mujer venezolana y a su relevancia en los acontecimientos nacionales.

\section{Marciano en su momento}

Si se elige la Venezuela de la década de los cincuenta como espacio de análisis del conflicto mujer-pasado, todo el problema teórico esbozado se complejiza. Si bien es cierto que en los últimos años de la década de los cuarenta, la intelectual venezolana comenzaba a ganar un lugar más sólido en el campo cultural, para los cincuenta, todavía no se habían delimitado del todo las funciones sociales y/o políticas que debía cumplir la escritora en el marco del perezjimenismo. O, lo que es lo mismo, si bien es cierto que para la década 19481958 en ninguna plataforma discursiva venezolana se pudo obviar la presencia de periodistas, escritoras, diputadas y gremialistas, también lo es que la valoración de su voz y sus acciones en el espacio público era sumamente ambigua.

El ideal desarrollista que dominaba las expresiones oficiales durante los cincuenta produjo en los medios de comunicación impresos toda una gama de significados nuevos, dirigidos a redefinir el lugar de las intelectuales. Una cadena de sentidos que, dada la celeridad con que se construyó, motivó la coexistencia -incluso a veces en un mismo ejemplar de diarios o revistas- de más de una manera de concebir la intelectualidad nacional y la participación de las mujeres dentro de su configuración.

En medio de estas circunstancias, aparecen la imagen y la escritura de Alecia Marciano, una autora encargada -en muchos de sus textos- de rememorar el pasado nacional y de dislocar los sujetos femeninos que lo pueblan. Al igual que otras de sus contemporáneas -como Isabel Leyzeaga, Cristina Ferrero, Gloria Stolk, Blanca Rosa López o Narcisa Bruzual- la vida y la obra de esta narradora ha sido vagamente reseñada en la historia literaria del continente, aún cuando su escritura coadyuvara a establecer la existencia de la mujer intelectual en el imaginario venezolano; 
se centrara en la diversidad y heterogeneidad de funciones y discursos asociados a las mujeres de mediados del siglo XX y, sobre todo, aún cuando demostrara su capacidad para dialogar y/o debatir con el poder y proponer modelos temporales, espaciales e históricos alternativos.

Por ejemplo, Yolanda Pantin y Ana Teresa Torres en El hilo de la voz (2003) se limitan a enumerar los libros publicados por Marciano, mientras que en el Diccionario general de literatura venezolana, editado por el Instituto de Investigaciones Literarias Gonzalo Picón Febres, se indica que la autora nació en 1920 en Valencia, Estado Carabobo, con el nombre de Alecia Margarita Muñoz y Giménez de Marciano y que se desarrolló como cuentista y novelista. Luego se agrega:

\footnotetext{
Estudió primaria y secundaria en Barranquilla (Colombia). En 1947 obtuvo el título de Técnico Avícola del Ministerio de Agricultura y Cría. Como cuentista ha colaborado en el suplemento Estampas de El Universal, en Páginas de Élite, El Mensajero, Ellas y El Diario de Carora. (S/A 1987: 301)
}

Resulta imprescindible mencionar que no se trataba de una autora con una sola obra -argumento que ha servido de soporte a la exclusión de la escritura de mujer de los estudios de literatura venezolana-, sino que entre las publicaciones de Marciano se encontraban: Bruja del Ávila (1957), Las coquetas (1957), El farol de Onona (1960), Amor en tres tiempos (1966), Gómez o los que se fueron (1977) y El verdadero amor de El Libertador (1983). Libros que, con excepción de Las coquetas, constituyen un aporte al mapa de ficciones históricas venezolanas. Todas las anécdotas construidas por Marciano recrean personajes excéntricos, enmarcados en grandes sucesos políticos como la Segunda Guerra Mundial, la Guerra de Independencia, la Conquista española o la dictadura de Juan Vicente Gómez.

No parece ser casual entonces que la crítica se haya abocado a revisar el único de sus textos que no plantea formas novedosas de rememoración o nuevas lecturas de la política. Por medio de la publicación de Las coquetas (1957), Marciano se agencia estratégicamente el semblante de ama de casa y, si bien da cuenta de la existencia de mujeres académicamente formadas, poseedoras de un saber positivista y capaces de insertarse en el aparato productivo nacional, también emite una serie de juicios de valor calcados de la prensa nacional de esos años. Ante ello, Plá y Beltrán -en la Revista Nacional de Cultura- establece:

\footnotetext{
Alecia Marciano tiene una pasión: la de denunciar y redimir. No le preocupa la hermosura, sino la eficacia. Su palabra, por ello, es como un látigo: golpea. Mas ¿qué golpea?¿A quién denuncia y pretende redimir?

En general, a la sociedad caraqueña; en particular a un grupo de seres profesionales de la medicina que viven, luchan y se angustian dentro de esa misma sociedad: las mujeres médicos [...] Al lado de la suciedad y la corrupción no coloca Alecia Marciano, como debería, el ideal de la mujer formada en el amor y el sacrificio por la profesión. Carecen de fe. Y ahí falta, o se autodenuncia, la tesis sustentada por Alecia Marciano: que el puesto de la mujer no está en la Universidad sino en el hogar. (Plá y Beltrán 1958: 175)

Del mismo modo, refiere:

La mujer, parece decir [Alecia Marciano], la pata quebrada y en casa. Nada de estudios. Nada de modernismos. Nada de libertades. Ante el pecado que pueda engendrar una mala entendida libertad, preferibles son el encierro y la muerte.

José Antonio Rial, comentando la obra de Alecia Marciano ha escrito: "Las Coquetas es la expresión de una protesta. La mujer caraqueña se encuentra hoy con una sociedad peligrosa. No se han roto los viejos y estrechos conceptos heredados de un ayer hipócrita y gazmoño, pero en este medio equívoco, que es el pequeño mundo capitalino de las gentes acomodadas, desaguan, traídas de aquí y de allá, ideas más liberales y más cómodas, que se hacen presentes en el juego diario de la conversación frívola etc. Pero que son auténticos escollos, en los cuales chocan y donde naufragan muchas confiadas bellas existencias". (Plá y Beltrán 1958: 176)
} 
Evidentemente, en la recepción de este texto, se acusan algunas particularidades propias del proceso de negociación subjetivo que formula la autora. Según Pla y Beltrán, en Las coquetas (1957), no se pueden percibir las confrontaciones expuestas por algunas narradoras venezolanas de los años cuarenta -como Lucila Palacios, Ada Pérez Guevara o Dinorah Ramos-, cuyos textos mostraban a una mujer en conflicto permanente con su entorno, sin pares posibles dentro de la sociedad y en medio de su lucha por la pertenencia. Cuando Alecia Marciano modifica esta construcción, el proceso de lectura de este también sufre importantes desplazamientos. Por ello, estrategias como "pasar por alto" la escritura, leer prescriptivamente la narrativa o bien sustituir el cuerpo del texto por el cuerpo de la intelectual - tan frecuentes dentro de la crítica literaria de los años treinta y cuarenta- en este caso son depuestas a favor de un breve comentario en torno a la trama de las novelas e, inclusive, a favor de una propuesta de apertura.

Dadas las exigencias de retrotraimiento dirigidas al sujeto femenino en el imaginario perezjimenista, mantener a la mujer en "su lugar", sin resistencia aparente de la subjetividad implicada, bien podía suponer una ruptura del binarismo en el que se basaba el dominio del sujeto masculino. Es decir, si la intelectual venezolana abandonaba los espacios sociales y políticos conquistados en las décadas precedentes y, tal y como se insinuaba en la publicidad, renunciaba a tomar parte del tejido discursivo de la Patria, el intelectual masculino hubiera quedado como el único poseedor de la voz nacional, por tanto, la polaridad se rompería y su poder hubiera quedado sin cimientos.

También está claro que no todas las voces masculinas reaccionaron del mismo modo frente a este estímulo. Por una parte, Pla y Beltrán ante la interpelación ejecutada por Marciano se ve en la necesidad de romper con los esencialismos en torno a la mujer que circulaban en la prensa nacional. Declara que si, ciertamente, el proyecto desarrollista del país no mentía al denunciar la peligrosidad representada por las venezolanas en el espacio público, también existían "las mujeres ideales", quienes sí habían invadido un territorio de conocimiento tradicionalmente reservado para los sujetos masculinos, pero lo habían hecho "por amor", con lo cual, su participación pública bien podía ser aprehendida como una extensión de la labor maternal.

Por contraste, se inserta el comentario de José Antonio Rial, quien lee peyorativamente el regreso de la mujer al hogar propuesto por Marciano, en tanto que supone una existencia residual de la "hipocresía" y los "conceptos gazmoños" de los cuales, el proyecto perezjimenista de nación debía - por su tendencia desarrollista- renegar; sin embargo, se sugiere que si bien estos rasgos conservadores no son elementos deseables, sí están presentes en la constitución del sujeto femenino venezolano. Por lo tanto, la carga de la prueba se invierte y, en lugar de leer a las mujeres "sucias y corruptas" de las que habla Pla y Beltrán como un peligro para la sociedad, se establece que la sociedad supone un peligro para unas individualidades incapaces de defenderse ante ninguna de las manifestaciones derivadas de la pugna tradición/modernidad.

Por su parte, Ángel Mancera Galletti, en ¿Quiénes narran y cuentan en Venezuela? (1958), expone:

Ya en prensa este libro, el 24 de diciembre de 1957 se terminó la impresión de una segunda novela de Alecia Marciano titulada Las coquetas, en la que la autora aborda el tema del ejercicio profesional de algunos médicos -especialmente médicas-, cuya deontología no sale muy bien parada de sus páginas. (Mancera Galletti 1958: 364) 
No sin antes aseverar:

\begin{abstract}
[Bruja del Ávila es] Historia con un sentido de la realidad, leyenda con un fondo dramático, permite a Alecia Marciano iniciarse en nuestra narrativa para dejar como una promesa que puede y debe realizarse en la novelística venezolana.

Y del periodista y crítico Julio Ramos son los siguientes conceptos, que resumen muy certeramente, la obra de Alecia Marciano:

La técnica literaria de Alecia Marciano no es todavía perfecta. Pero Bruja del Ávila es amena y está escrita con claridad, sin artificiosidades de estilo destinadas a deslumbrar a los incautos. Su obra, repito, es primigenia. Adolece, por ende, de descuidos en lo que toca al desenvolvimiento lexicográfico, pero esa falla no deja de estar asaz compensada por el acierto y colorido en la descripción de la naturaleza y de las costumbres comarcanas de Galipán. (Mancera Galletti 1958: 364)
\end{abstract}

Tras leer estas acotaciones donde se contrasta la recepción de Las coquetas (1957) y la de Bruja del Ávila (1957) se hace obvio que el semblante autoral elegido por Alecia Marciano para poner en circulación su escritura le permitió en poco tiempo, realizar una experimentación estilística que si bien fue interpretada -por tres de los cuatro críticos referidos hasta el momento- como una deficiencia estética, nunca deterioró su legitimidad como intelectual. Desdecir el planteamiento social de esta autora hubiera supuesto negar muchas de las propuestas historiográficas y mediáticas de la Venezuela de los cincuenta, lo que -una vez más- ilustra la eficacia de este proceso de negociación.

También resulta curioso que, aún cuando hace eco de las deficiencias formales de Las coquetas y Bruja del Ávila, Mancera Galletti reconoce que tanto en el ejercicio discursivo de Alecia Marciano, como en la vida misma de las médicas frívolas y excesivamente independientes que esta autora perfila, existe una deontología, un trazado y un conocimiento de los deberes que atañen a cada individualidad, por tanto, el crítico les confiere la condición de sujeto del saber y sujeto de la moral -aunque resulten incompatibles entre sí- a ambos constructos.

Del mismo modo, Julio Ramos habla de una descripción, tanto de la naturaleza como de las costumbres, elaborada con "acierto y colorido", lo que -de forma sutil- equivale a admitir la cercanía de Marciano con el conocimiento. Evidentemente, si la autora puede reproducir "con acierto" las cosas que ha visto es porque la narradora las recuerda con una mirada aceptable por la autoridad, de aquí que de algún modo la escritora esté siendo tomada como experta en ciertos lugares de saber. Curiosamente, esta propuesta se reitera en la nota preeliminar de la novela Bruja del Ávila (1957), pero esta vez el comentario es formulado sin tener en cuenta los anacronismos, las fragmentariedades y los pastiches contenidos en la elaboración de la novela.

Es pertinente recordar que en Bruja del Ávila se ficcionaliza a Anna Knoche, una mujer europea fallecida en 1879, en el personaje de Marina Kehrr, habitante de San José de Galipán en la década de los cuarenta. Esta protagonista anacrónica se involucra con Silvestre, un joven caraqueño quien, gracias a los empeños de su madre, ha logrado destacarse en el mundo de la política. Cuando estos dos personajes se conocen, Silvestre está de paso por Venezuela y desea regresar a Suecia donde trabajará como agregado en la embajada. Marina, por su lado, es una joven encantadora que soñaba con ser una gran pianista y vivía con su padre, un médico alemán dedicado al embalsamamiento.

La novela comienza a desarrollarse en la ciudad de Caracas. Silvestre y Dolorita, su madre, se encuentran en una fiesta que ella solía organizar cada jueves. A esta celebración asistían distinguidos personajes del mundo político caraqueño junto con sus hijas casaderas, pues el nuevo interés de Dolorita era encontrar una esposa para su hijo. La candidata 
preseleccionada por la madre era Lucía, una viuda joven de gran belleza y sensualidad. Silvestre se veía inmensamente atraído por ella.

A pesar de esto, el protagonista tenía otros asuntos pendientes, pues un hermano de su padre le había heredado una hacienda ubicada en el cerro el Ávila, en el mismo pueblito habitado por Marina. El detonante de la historia es la única petición formulada por el tío como condición para recibir la herencia: vivir en Galipán, dentro de la hacienda "Las Brumas", por treinta días. Durante ese período, el personaje masculino experimenta en un dilema constante, puesto que aquel mundo político que él había creído suyo comienza a parecerle ajeno. Silvestre, como la alegoría de su nombre permite adivinar, se siente cómodo con las tareas del campo y, sobre todo, con la compañía de Marina Kehrr, quien entre tanto encuentro y charla también se enamora. Cuando todos en la hacienda comienzan a preocuparse por la notable insistencia de uno en el otro, Silvestre decide casarse, pero al comunicárselo al doctor Kehrr, este le advierte que eso no es posible, porque Marina sufre el mismo mal que su madre, una mujer que había muerto y había sido momificada algunos años atrás.

El médico añade que el clima de las montañas era lo único que hasta el momento les había permitido detener la leucemia. Posteriormente, le aconseja al pretendiente que se marche a sus labores y agrega que si el amor es tan grande como el que profesa podrá esperar a que Marina se encuentre segura. Silvestre no está del todo dispuesto a irse y el mes en "Las Brumas" se extiende. Dolorita, preocupada por la ausencia de su hijo y por las locas ideas del tío muerto, decide ir en su busca. Sube a San José de Galipán acompañada de Lucía. Durante la visita, Silvestre logra ver en Lucía a una mujer sensual, pero ahora no se siente atraído por ella. La mujer de ciudad, celosa y resistida a la derrota, se niega a perder a su antiguo pretendiente. Mientras todos van paseando por la montaña, ella arma un plan para lastimar a Marina y cuando lo lleva a cabo, sin querer, le ocasiona la muerte. Silvestre decide permanecer en Venezuela y, aunque sigue con su vida, nunca logra superar su relación con Marina, ni abandona el proceso de formación subjetiva al que fue sometido en contacto con ella.

Como se ve, Bruja del Ávila (1957) constituye una obra muy difícil de definir en el mapa de escrituras de Alecia Marciano, una narradora que había conseguido -sin aparentemente haberlo solicitado- autorización expresa de la intelectualidad venezolana, para transgredir los límites de la participación pública de las mujeres. Hay una nota que presenta este libro, firmada por L. Ll., en ella se propone que la novela de Marciano:

\footnotetext{
Se basa, en la parte central de la trama, en un hecho de la realidad venezolana. Propiamente hablando, de la realidad caraqueña: la existencia de un extravagante científico de nacionalidad alemana en la zona del Ávila denominada Galipán, a fines del siglo pasado [es decir, del XIX] y comienzos del presente -el doctor Kehrr en la novela- que construyó una sólida y confortable vivienda en Galipán y allí pasó el resto de su vida. Había levantado, vecino a la casa, imponente mausoleo, con tres sepulcros: uno en el centro para él y los de los otros lados para dos damas hermanas, de su misma nacionalidad, que por temporadas y alternándose, lo acompañaban en la aislada mansión. Además, en un desván de ésta, conservaba momificado el cadáver de un soldado de los del famoso guerrillero del Ávila, Antonio Romero. (En: Marciano 1957: 7)
}

Hay, sin duda, un ejercicio de autolegitimación por parte del prologuista, quien si bien admite que la autora "se basa" en una realidad caraqueña, suministra una serie de datos en torno a estos "hechos verdaderos" omitidos por Marciano en su ficción. Aún más, L. Ll. aclara -al menos de forma solapada- que él sí conoce las fechas reales de la historia de ese hombre que vivió en Galipán, lo que sirve para poner bajo sospecha la novela que, según este experto, "adolece de defectos [...] que la autora superará con el tiempo" (7). 
De este modo, la particularidad que subyace al hecho de que Marciano elija o, como mínimo, acepte que su obra sea introducida con una nota como esta, también es relevante. Evidentemente, en este breve texto emergen una serie de elementos asociados al ingreso de las intelectuales en el campo cultural venezolano que, por extensión, le otorgan a la autora un perfil útil para la enunciación. Por ejemplo, según la crítica, esta obra es deficiente, por tanto no demanda ninguna censura sobre el juego temporal o los anacronismos usados en su interior. Aún cuando estos saltos de tiempo se pudieran leer como una negación del supuesto progreso experimentado en Occidente, en las mismas fechas en que Marciano enmarca la vida de sus personajes, no llama la atención de los lectores. O, y esto es quizás más obvio, aunque las inconsistencias temporales develen la retracción ética y moral que surgió en Venezuela tras el ascenso de perezjimenismo continúan pasando desapercibidas.

Del mismo modo, en medio de su demostración de erudición, el prologuista refiere algunos textos inéditos de Rómulo Gallegos. Específicamente, afirma:

\begin{abstract}
El tema [de la momificación de Antonio Ramos] sirvió de inspiración a Rómulo Gallegos, para escribir uno de los muchos dramas en que el consagrado autor ejercitó su pluma, pero de los cuales no publicó ninguno. En compañía de Enrique Soublette, de sus camaradas de La Alborada, Gallegos visitó la casa del médico alemán, cuando ya éste había muerto y reposaba en el sarcófago central. La mansión, que entonces se conocía como "La casa de las madamas", estaba habitada por las mencionadas compatriotas del doctor, en avanzada edad, que esperaban para ir a llenar los sepulcros vacíos. Gallegos tituló su drama Las madamas. (En: Marciano 1957: 7)
\end{abstract}

Quizás en su empeño por demostrar la inestabilidad del discurso de Marciano, L.Ll acaba por emparentar -al menos temáticamente- su propuesta con la de uno de los grandes fundadores de discursividad (Foucault 1984) en el canon literario venezolano. Entonces, nada de lo escrito dentro de los márgenes de la novela podría resultar inadecuado para las demandas del campo cultural sino que a lo sumo, y haciendo un gran esfuerzo por cuestionar la expresión, tan solo podría considerarse mal formulada.

Hay pues, en esta obra, un abanico de sujetos y lecturas que insta a comprender la prospección temporal en contraflujo. El punto de partida de Marciano es la reescritura de la mujer venezolana y, sobre todo, la revisión de su pasado para poder pensarla en medio de una genealogía. Con este fin, exacerba la forma especulativa de la filosofía de la Historia antes que el carácter argumentativo de la ciencia histórica. Sustituye la estructura explicativa característica de la recuperación del pasado nacional, por una narración generadora de territorios de pertenencia e identidades.

\title{
3. Mujer y pasado en Bruja del Ávila (1957)
}

Uno de los primeros elementos que llaman la atención al leer Bruja del Ávila, es que la autora nunca pone en duda la pre-existencia de más de una tipología de venezolanas con discurso y capacidad de autoafirmación. Por el contrario, para Marciano una mujer ciudadana como Dolorita, por ejemplo, tiene tanto tiempo circulando por el espacio público que corre el riesgo de desaparecer del mapa subjetivo nacional. Del mismo modo, en esta obra, se plantea una serie de opciones ser para las mujeres venezolanas que trasciende los estereotipos de género.

Ciertamente, al momento de perfilar los personajes femeninos, la voz narrativa se vale de algunas representaciones publicitarias: 
Dolorita podía ayudar, subir, según su criterio lo indicara, su opinión era tenida muy en cuenta. Políticamente era ecuánime y sincera; de figura no muy alta, algo regordeta, de regulares facciones algo ajadas, pero sus arruguillas muy disimuladas por el maquillaje, adornada siempre con magníficas y adecuadas joyas, con una elegancia natural que la caracterizaba, era el prototipo de matrona caraqueña, sonriente, muy ocupada, cuando no con lo propio con lo ajeno. (Marciano 1957: 13-14)

A pesar de ello, desplaza ligeramente algunos tipos estandarizados. Tal como se desprende de esta presentación, Dolorita no nació con la belleza necesaria para ornamentar el espacio público - tal y como lo hubiera determinado la representación publicitaria de las venezolanas en la década de los cincuenta-, eso la obliga a asumir una actividad en la cual su marido se ha destacado y, al mismo tiempo, le ha dado cabida. La única exigencia formulada es que permanezca al interior del hogar $y$, obviamente, que funja como una suerte de madre o figura protectora para los políticos jóvenes.

Empleando otros términos, la esposa obediente que sigue los designios de su marido acaba por erigirse dentro de esta obra en una subjetividad política; no obstante, a diferencia de la situación real de las intelectuales que habían peleado por los derechos civiles de las venezolanas, Dolorita no puede ser censurada por su conducta. Ella realiza todas sus acciones bajo la supervisión de un hombre y al interior del hogar, lo que, progresivamente, amplía el poder de este personaje.

En segundo término, si bien se admite que "la política" no es agraciada, no se llega a presentar como solitaria o poco deseable, sino que -por el contrario- esta mujer es descrita como "adornada" y, aunque esta referencia sea sutil, su representación resulta menos extemporánea con respecto al entorno que la figura de Lucía. De hecho, aunque ambos personajes son viudos -es decir, ambas mujeres se han erigido como sujetos del deseo en algún momento de sus vidas-, sólo Dolorita ha sido madre, por ello, aunque se trate de una ciudadana, su presencia resulta más inteligible para el imaginario perezjimenista.

De igual forma, hay una distancia clara entre la evaluación moral de la "camarilla de políticos" y la de una mujer "ecuánime y sincera", lo que exhorta a reflexionar en torno a la construcción de la modernidad venezolana formulada Alecia Marciano: ¿La modernización es acaso la generadora de los vicios?, ¿debe ser leída a partir de los actores que circulan en su interior?, ¿es, finalmente, una superficie homogénea que alcanza a todos los individuos por igual o una condición destinada a unos pocos?

Un pliegue interesante a este respecto se produce cuando la mujer ciudadana elige como posible pareja para su hijo a una "mujer fatal", un gesto que no sólo moviliza a Lucía, sino también a su par masculino:

\footnotetext{
Silvestre acababa de llegar de Suecia a donde volvería como agregado a la Embajada. Los asuntos eran tan delicados que, como persona de confianza, le entregaron un mensaje de gran importancia. Había cruzado la Alemania Nazi y allí estaba su casa, repleta de las más importantes personalidades políticas interesadas en sus magníficos relatos sobre el país que trataba en esos momentos de dominar al mundo. Nuestro protagonista, como buen diplomático, hablaba de todo y para todos pero, en resumidas cuentas, ¡de nada! Los jueves de su madre habían sido siempre un éxito, éste lo era más; los embajadores habían acudido con sus hijas casaderas pero, no tenía Silvestre esa tarde ojos más que para Lucía (Marciano 1957: 15)
}

En este fragmento, está contenida la primera referencia histórica concreta de la obra, y si bien no hay una postura política perceptible al momento de aludir el desarrollo de la Segunda Guerra Mundial, la falta de claridad ideológica no es atribuida a la autora ni a la voz narrativa marcada como femenina, sino a la condición de diplomático de Silvestre, quien pese a ser hombre -o precisamente por ello- reconstruye de manera superficial su experiencia. 
Sin duda, este "hablar mucho, sin decir nada" adjudicado al co-protagonista, no es más que la reinscripción en un cuerpo masculino, de una de las características definidas en los medios de comunicación social de los cincuenta como propias de las mujeres. Lo que acompañado al uso alegórico del nombre "Silvestre", invierte por completo el signo bajo el cual se leía a "la venezolana ideal" para el proyecto desarrollista y, a partir de cuya interpretación, se justificaba el reingreso de las mujeres en el hogar.

Es decir, el personaje masculino -como los protagonistas de las obras regionalistasregresa del viaje a un país dirigido por la racionalidad, pero al volver todavía conserva su condición "silvestre" y su incapacidad para articular un discurso político verosímil. Por eso, difícilmente podría asumir una actitud didáctica frente a quienes habitan el territorio caótico por organizar. Al contrario, estas condiciones establecidas por la autora al momento de construir a Silvestre lo insertarán en un proceso de iniciación, en procura de una formación y de una identidad.

Paralelamente, los otros tipos sociales representados dentro de la obra se complejizan. De este modo, la mujer artista pasa de ser una entidad conflictiva a ser la mayor representante de la sumisión femenina, mientras que el arquetipo de la madre adquiere una volatilidad poco común en su construcción. Francisca, la primera pianista construida en la novela, constituye un buen ejemplo de esta movilización. Cuando en medio de una reunión se le pide que interprete una pieza "de Listz, Chopin, el valse Oubiliée del tempestuoso Franz" (16), ella responde que no tiene en su repertorio ninguno de los temas solicitados porque "el profesor Zapanini ha dicho de mí: 'Sólo podrá tocar bien a Hydn, Mozart, Schumann'. - Toda la dulzura de su ser estaba en esa negativa” (16). Algunas páginas después, se señala que la madre de Silvestre:

\footnotetext{
Con la dualidad que caracteriza a las mujeres, pasando maravillosamente de la alegría a la tristeza o del dolor al regocijo, Dolorita, cambiando la expresión mortificada de su rostro, obsequió a don Jesús con su más hermosa sonrisa.

Silvestre observaba a su madre mientras hablaba, la notó decaída y demacrada, sus ojeras eran profundas y se notaba mucho su maquillaje; era como una hermosa flor marchita. Sintió una infinita compasión por ella. (Marciano 1957: 25- 26)
}

En este fragmento, se hace obvio que, desde la perspectiva del protagonista, todos los estereotipos femeninos que lo rodean están fuera de tiempo y lugar. La mujer frívola ha envejecido, la mujer músico ha sido domada, mientras que la madre ha perdido su condición universal y ha comenzado a ajarse. Ciertamente, en este texto, no se da cuenta de lo que ha ocurrido con los hombres encargados de diseñar la nación; sin embargo, la pérdida del vigor de las mujeres-tipo, resulta un desencadenante suficientemente poderoso para iniciar un viaje épico.

En este contexto, resulta verosímil que Marina se erija como otro sujeto problematizado. Partiendo desde su misma descripción física, esta mujer contraviene todas las representaciones prescriptivas de la identidad femenina que circulaban en los medios impresos de los cincuenta:

Las velas de la cruz brillaban y parecían que bailaban alegremente, el ambiente era delicioso. El doctor y Silvestre se acercaron a la reunión para contemplar mejor, y así el joven se encontró ante la mujer más extraña que en su agitada vida de trotamundos había visto.

¡Marina!

Ante él se erguía pálido y bello el rostro de la joven. El cabello era color bronce, los ojos enormes, azules orlados de pestañas negras; sus labios tenían el rosor (sic) y suavidad del de los niños, La blancura de la blusa hacía resaltar la de ella, y su amplia falda de flores le hacían (sic) parecer más hermosa que la realidad. Era frágil como una porcelana china. Esa tarde Silvestre se hizo mozo de pueblo. (Marciano 1957: 40- 41) 
Resulta muy sugerente que, a diferencia de lo que ocurre con las protagonistas de las otras obras, en Bruja del Ávila se "extranjerice" a esta mujer. Un sujeto femenino cuya única característica expuesta hasta el momento es la imposibilidad de reconocer las diferencias sociales y culturales aportadas por el pensamiento racional en el diseño de la sociedad venezolana. Sin duda el hecho de que Anna Knoche, el personaje histórico en teoría representado por Marina Kehrr, fuera una europea fallecida en 1879 hace que su definición como portadora de "cabellos color de bronce" y piel "de porcelana china" no resulte del todo inverosímil. Pese a ello, la (re)ubicación del personaje en la década de los cuarenta invita a reflexionar sobre la nueva función de este estereotipo dentro del imaginario nacional.

Alecia Marciano sobre-estetiza a su protagonista y la acerca a la plástica decimonónica hasta el extremo en que la convierte en una referencia paratextual. Una suerte de evocación de pinturas y esculturas románticas, muy útil para diversificar la construcción mediática de la "mujer criolla" y para romper, a la vez, con el universal de belleza que se quería establecer en los medios de comunicación social de los cincuenta.

En distintos momentos de la novela, se va a confrontar esta diversidad de forma explícita y con finalidades diferentes. Por ejemplo, cuando Silvestre redacta una descripción y, posteriormente, una comparación de Lucía y Marina en su "libro de notas", convierte la escena de la lectura ${ }^{4}$ en un hecho paradójico. Tras haber leído buena parte de los libros que le legó su tío en la hacienda "Las Brumas" o, dicho en otros términos, tras haber "consumido" una multiplicidad de voces e interpretaciones del pasado, el protagonista masculino de Bruja del Ávila no deviene escritor, sino un sujeto enamorado que afirma:

“Por qué me gusta Marina?”

Sólo unas cuantas veces le había hablado, se contentaba con mirarla, en esto se le iba el tiempo, nunca ante sus ojos francos, se atrevía a demostrarle su admiración. Dábale la impresión de una hermosa y blanca flor que no podemos tocar por temor a deshojar con nuestras manos ásperas. Eso era él, un hombre áspero de mundo ante algo tan puro y tierno que daba temor rozarlo. Ahora sabía por qué le atraía la joven; era el producto mixto de la escuela de su madre y sus propios gustos. (Mariciano 1957: 68)

Del mismo modo, Silvestre habla de Lucía, la mujer que aparece en las primeras páginas del texto y que, según la voz narrativa, "había empezado a envejecer", señala entonces:

\footnotetext{
También sabía por qué le atrajo Lucía, había sido un problema que quedaba descifrado: "Desde chico en el mundo en que vivía, sólo se alababa y se admiraba todo lo florido, lo brillante, lo artificial y lo refinado. Sus gustos se desarrollaron en esta dirección, Lucía contenía todo esto, un refinamiento especial para saberse pintar y acicalar, con los mil ardides de la coquetería femenina, que en sí constituyen un arte; le gustaba como les gustan a los niños los pájaros de colores; pero su otro yo, aquel que llevaba escondido y que ahora aparecía anhelaba algo más profundo, algo que fuera más natural, más real, que dependiera de las eternas circunstancias. (Marciano 1957: 69)
}

Según lo escrito por el protagonista, una vez que ha sido iniciado en la mixtura de los textos, tanto la mujer frívola y condenada a desaparecer que encarna Lucía, como la dama espiritual, ajena a cualquier vicio urbano, representada en Marina, van a develar una gama de inconvenientes al momento de su evaluación, pese a lo cual -o quizás precisamente por esopudieran erigirse como deseables y útiles dentro del proyecto nacional en construcción.

A esto se suma que ninguno de estos dos personajes va a compartir el perfil con la voz narrativa, tanto menos con Alecia Marciano: ninguna de ellas escribe, ingresa al campo cultural venezolano, ni -mucho menos- sugiere soluciones simbólicas para los conflictos de identidad sufridos dentro del territorio nacional. Por el contrario, en Bruja del Ávila, Lucía y Marina se presentan como entidades dispuestas a ser delimitadas desde cualquier lugar de 
autoridad, por ello, tras leer esta novela se hace necesario reflexionar sobre cuál es el tipo femenino que perdura en el tiempo, dónde lo inscribe Alecia Marciano y en qué territorio de su negociación con el pasado olvida a las esencialidades representadas en la prensa nacional.

A este respecto, se debe tener en cuenta que tan solo en la segunda mitad de la novela, la identidad de Marina como "Bruja" se explicita por primera vez. Únicamente cuando la protagonista rompe los paradigmas cognitivos de su pareja, pasa a ser definida a partir sus poderes extraordinarios:

\footnotetext{
Marina sacó de su pecho un pañuelito y lo agitó en el aire, se agarró de la mano de Silvestre y quiso descender corriendo, pero él la atajó y [Silvestre] le preguntó curioso:

- ¿qué ruido es ese que haces con el pañuelo?

Era un sordo ti, qui, tac.

- Como no vemos muy bien, esto servirá para ahuyentar las serpientes, son cascabeles de la culebra.

- ¡Nunca pensé que creyeras esas cosas!

- ¿Por qué no? Nita las arregló especialmente para mí, puedo correr por los montes sin temor, esto espanta los malos bichos.

-En resumidas cuentas, que eres una pequeña bruja. ¡Hechicera de la montaña!

La niebla invadía todo y agarrados a Pascual que hacía de guía, comenzaron a bajar. Marina siguiendo el juego de Silvestre le gritó:

—_Agárrate duro, inocente pajarillo, si no quieres ir al infierno! (Marciano 1957: 103)
}

Desde la tensión planteada entre Marina y Lucía, se hace todavía más obvia la réplica que contiene la representación de "la bruja" en el imaginario venezolano de los cincuenta. Vale la pena recordar que, en sus orígenes, el arquetipo de la bruja estuvo asociado al descontrol de la potencia sexual femenina y su expresión pública. Una bruja, por definición, debía ser una mujer sin pares posibles dentro de la sociedad que, como consecuencia de su autonomía, desvirtuara su capacidad erótica hasta convertirla en perniciosa.

A esto se suma que las brujas también luchaban contra la prospección temporal, pues su sexualidad no era productiva, ellas no solían detentar cuerpos fértiles y su existencia demandaba una discursivización que les permitiera a quienes les temían, conjurar sus capacidades extraordinarias. Sólo por medio de la palabra y el rito, la sexualidad femenina podía ser regulada y normatizada, lo que podía aplacar la existencia, el poder y el conocimiento implícito en este arquetipo y acercarlo a una figura más manejable como la de la madre.

En el pensamiento occidental, particularmente, esta polarización de las identidades femeninas ha traído como consecuencia que se sobresexualice la representación física de las brujas, al extremo de atribuirles un cuerpo grotesco, sombrío y desagradable. Lo que, en resumidas cuentas, permite comprender la imagen de las brujas como mujeres solteras o, a lo sumo, matrimoniadas con el diablo, cargadas de maldad y/o locura, y portadoras de una peligrosidad derivada tanto de su atractivo sexual como de la imposibilidad de controlar sus formas de saber.

Pese a ello, dentro de la obra de Marciano, Silvestre no sólo confiesa ser ajeno al saber de Marina sino que, además, desestima que el mismo constituya una forma de conocimiento; en segundo término, acerca al personaje femenino al campo de la anomalía y, al hacerlo, emplea un vocablo que refiere insania mental; además, la representación de la sexualidadsensualidad de la protagonista, si bien se hace en términos un tanto ambiguos, se trasluce a lo largo de todo el texto; con lo cual, resulta innegable que el apelativo de "bruja" calzaría a la perfección con la lectura que ha realizado el protagonista de su pareja.

Sólo quedaría preguntarse entonces ¿por qué si se trata de una hechicera, que además habla del "infierno" - significante prohibido en el vocabulario femenino- este personaje se 
erige como un sujeto deseable?, ¿por qué la movilización física, geográfica y subjetiva del protagonista no desemboca -dentro de un texto que se declara discursivizador de la "realidad" caraqueña- en la capacidad de juzgar y excluir, sino la de evaluar y tratar de acceder a las formas de conocimiento no racionales? La teorización que realiza la autora en torno al pasado puede brindar algunas respuestas al respecto.

\section{El reflujo de la historia: extranjeros y momias en el pasado nacional}

Para pensar la relación que establece Alecia Marciano con la memoria, se hace necesario revisar la elección de sus referentes narrativos. Esta autora no reconstruye el pasado a partir de un mítico doctor Alemán llegado a Venezuela algunos años antes -como lo hizo la Historia-, ni de los acompañantes de este excéntrico personaje -como hizo el escritor Rómulo Gallegos-, sino de la hija del doctor Knoche (o Kehrr), portadora de una serie de representaciones mediáticas de los sujetos femeninos que circulaban en prensa por los años cincuenta. Una mujer -usufructuaria de códigos de expresión particulares- cuya existencia sólo quedó registrada superficialmente tanto en los años que vivió, como en los artículos que muchos años después se editaron para rememorar la figura del médico.

En 1971, el diario caraqueño El Universal contenía una nota que llevaba por título "Desde los Welser al Doctor Knoche", la misma aparecía ilustrada con una foto del científico alemán y otra de su hija "Ana Knoche". En el texto, se establecía una panorámica de la migración alemana en Venezuela, que comenzaba en el siglo XVI y acaba en el XIX. En el párrafo final se planteaba:

\footnotetext{
Algunos [notables alemanes del XIX] se integran al medio o dejan importantes trabajos de investigación. Entre todos estos quizás el más interesante personaje que nos visitara por aquel tiempo fue el célebre y enigmático Dr. Gotfried Knoche, cofundador del Hospital de San Juan de Dios de La Guaira, inventor de cierto líquido momificado, con el cual embalsamara el cadáver de nuestro famoso político Tomás Lander y más tarde, retirado a una pintoresca posesión que adquiriera cerca del Picacho de Galipán, construyó allí una casa semejante a las que existían en la Selva Negra con biblioteca y laboratorio. Desde su retiro experimentó su descubrimiento con sus empleados y familiares en la medida en que estos iban falleciendo. Mediante su procedimiento los sometía al proceso de embalsamamiento y vivió entre ellos, hasta que rindió la jornada. (Schael 1971: 190)
}

Si bien la figura del científico cargado de saber positivista es edificada sobre y a partir de un cuerpo masculino, en este fragmento, se habla de un personaje que -tal y como lo hace la autora al escribir Bruja del Ávila-, suspende la prospección temporal y embalsama las subjetividades hasta romper con la idea de progreso. Es un varón que, pese a su condición de médico, detiene el curso del tiempo y consigue atentar contra la moral desarrollista. Sin duda, la taxidermia en sí misma constituye un territorio complejo, pues si se entiende el acto de momificar como el gesto de "salvar" de la putrefacción un cuerpo, bien podría definirse esta actividad como una desnaturalización de la muerte.

A pesar de ello, al convertir los cadáveres en objetos manipulables, además de la dosis de artificiosidad ya mencionada, se le estaría añadiendo a la muerte cierta materialidad. Es decir, si bien el doctor Knoche, reconstruido por Alecia Marciano como el padre de su protagonista, se dedica a rehuir el fin de la vida, con su oficio abre un espacio para edificar este proceso -temido y esperado por todos los hombres- como un monumento digno de adoración y respeto, lo que impide comprender por qué se caracteriza al personaje como dueño del saber científico. 
A esto se suma el cuestionamiento del lenguaje por parte de la autora. La palabra escrita y, en ocasiones, también la oralidad serán presentadas por Alecia Marciano como formas insuficientes, encargadas de generar más angustia que información certera. Por ejemplo, la primera historia que le cuentan a Silvestre acerca del doctor Kehrr está llena de vacíos y tensiones. De igual forma, Don Francisco comenta que quienes trabajan para este médico "si antes hablaban poco, ahora menos [pues] son dos apasionados del amo y le imitan hasta exagerar" (49).

Se podría afirmar, entonces, que Alecia Marciano propone una reconstrucción del pasado sin discurso, un postulado que se manifiesta sobre todo cuando la autora negocia su voz y su identidad dentro del campo cultural de los cincuenta. En esos episodios, Marciano propone la existencia de una Historia de los afectos, de un pasado que muestra el progreso organizado y necesariamente predecible de los nexos emotivos, cuyas finalidades principales serán unificar el flujo pasional y otorgarle un carácter manejable en el marco de un proyecto de nación como el perezjimenismo que se encontraba, al menos en teoría, dominado por la lógica racional. Entonces, historiar el afecto supondrá legitimar la emocionalidad como elemento reconocible por la alta cultura y otorgar un territorio de arraigo a los individuos involucrados en los intercambios afectivos.

Por ello, resulta verosímil que el tío Espinosa -el pariente de Silvestre que lo obliga a residenciarse en Galipán- sugiera la existencia de una verdad en la literatura y ayude a des-institucionalizar el saber histórico. Al hablar de objetos que poseen "una historia", el tío Espinosa deja claras la amplitud y la diversidad del pasado, en oposición a la univocidad y la jerarquización propuesta por la historiografía. Del mismo modo, al equiparar a "la gente que nos rodea" y "sus libros", este personaje masculino inscribe tanto la letra como las individualidades que permanecen en la periferia urbana en un pasado, que no sólo existe sino que además, puede y debe ser "leído", lo que invita a pensar en otra de las tensiones, con el proyecto desarrollista, contenidas en Bruja del Ávila.

Si, como la lógica del proyecto perezjimenista indicaba, la razón debía perpetuarse en tanto instrumento de medición de los individuos, de su inscripción dentro de la historia y, sobre todo, en tanto garantía del progreso nacional, esta propuesta de reconocer la(s) historia(s) protagonizada por otros personajes, desde otros espacios y narrada por otras voces, sería altamente contraproducente; pese a ello, este gesto contestatario pasa desapercibido ante la crítica que abordó la obra de Marciano, pero no se pronunció en torno a su legitimación de un saber alternativo a la lógica positivista.

Esta indiferencia de la Academia obliga a preguntarse: ¿Qué dice esta autora sobre la noción de "verdad" en su proceso de negociación con la memoria?, ¿qué papel cumple el conocimiento verificable en la reconstrucción, con todos los matices antes expuestos, de una historia alternativa? La contaminación de registros que se produce en Bruja del Ávila reaviva la pugna entre verdad y sentido. En primer término, Alecia Marciano establece como mínimo dos territorios de saber obviamente diferenciados: por una parte, estará el terreno de "la verdad racional" a la que puede ingresar sin trabas aparentes y, por la otra, se encontrará el lugar de "la verdad del sentido", perseguida por el tío Espinosa, adquirida por Silvestre y detentada por Marina. Coexistirán entonces una verdad universal y una verdad con sujeto e historia, engendrada en el intercambio humano y cuya inscripción en el pasado resultaba fundamental; no obstante, a medida que avanza el texto, se instituye que puede haber intersubjetividad, afecto e, incluso, sentido, sin una verdad que la soporte. 
Este dato resulta interesante si se piensa en la decisión de Marciano, de no atribuir a las mujeres "esenciales" -ni siquiera a Marina, quien es descrita como poseedora de "una mirada de quien no tiene dudas y sabe siempre a donde va" (69)- reflexiones en torno a los hechos de política contingente. Por ejemplo, los comentarios sobre la Segunda Guerra Mundial son enunciados por la voz de Silvestre, aunque este personaje les imprime una afectividad poco esperable de un diplomático. Ciertamente, la rememoración del holocausto se desencadena cuando el protagonista escucha a Marina tocar el piano ${ }^{5}$; sin embargo, sigue estando a cargo del varón letrado, sólo que por las modificaciones identitarias que ha padecido, inserta el enfrentamiento bélico en el territorio de la memoria emotiva:

\footnotetext{
Al instante [Silvestre] reconoció el concierto [que interpretaba Marina], lo había oído tocar en Berlín por un gran pianista judío ${ }^{6}$, al que habían cambiado el nombre para poder presentarlo ante el público esa noche.

Para su suerte o mayor desgracia aquel hijo de Israel era rubio. Antes había sido condenado a los campos de concentración, pero alguien lo necesitó ese día para halagar los oídos de Hitler consultado aquél, sobre la raza y el problema, otro había insinuado.

- ¿Tiene el cabello negro?

-No, es rubio como un Sigfred

- Pues entonces no hay problema, haga germano su nombre y si aprecia la vida, jamás recuerde que tiene sangre judía, que se olvide de su padre y de su madre, su vida depende ahora de un gesto de reconocimiento hacia ellos ¡De ahora en adelante, debe ser un fiel alemán al servicio del Führer! (Marciano 1957: 70)
}

La melodía que interpreta esta mujer que "unía a su belleza espiritual, el atractivo personal que impresionaba su mente" (69) sirve para proponer una reconstrucción de la Historia poco convencional. Por primera vez $-\mathrm{y}$ a partir de la sensibilización que sufre el protagonista masculino gracias al contacto con la música-, Silvestre se atreve a fijar una posición política clara y a callar "diciendo algo". Es decir, abandona el territorio que le correspondía como diplomático y varón ilustrado, para establecer un vínculo intersubjetivo con un personaje de la Historia que, en una suerte de antagonismo significante, está obligado a negar su pasado, para elaborar un presente.

Al igual que en el proceso de negociación que lleva a cabo Alecia Marciano con una historia legendaria de su comunidad, el pianista se ve en la necesidad de construir su pasado en términos dicotómicos y, como consecuencia de ello, excluyentes. Ahora bien, si el presente donde Marciano, Marina, Silvestre o el pianista desean circular no estuviera erigido sobre una tensión, sino sobre un pacto, la rememoración podría transformarse en un espacio para representar identidades imaginadas y, al mismo tiempo, apropiárselas e incorporarlas como sentidos funcionales en el diseño del presente.

Esta negociación -necesaria ante situaciones de riesgo como las vividas en la Segunda Guerra Mundial- permite comprender la Historia, más que como un registro secuencial de los hechos, como una plataforma utópica donde se pueden objetivar y, a la vez, transformar las marcas de identidad impuestas desde el poder. Los procesos de exclusión siguen existiendo y, al parecer, ninguna de las identidades marginadas puede evitar su represión; no obstante, los significados no negociados permanecen hasta el momento en que la individualidad en tránsito se decide a darles voz. Sin duda, el episodio rememorado por Silvestre en Bruja del Ávila tiene un final aciago y, en apariencia, desesperanzador; no obstante, al recordarlo, el mismo protagonista sufre una movilización subjetiva que pluraliza los desenlaces posibles de la propuesta inicial, e invita a pensar en otro de los usos posibles de la Historia: 


\begin{abstract}
El público pidió música de Bach a la que era muy adicto el Führer que no cesaba de aplaudir, él los complació; pero de último, para terminar, interpretó algo tan suave, dulce y lleno de pasión, que cautivó a todo el auditorio, haciendo parar al Estado Mayor, que obedeció a una orden del dueño de Alemania. Era la sencilla Invención número trece del gran Juan Sebastián, un Allegro que comenzó el artista como tal pero tan lleno de dulzura y de dolor, que era como contar con las notas su tragedia; un final, "sempre in crescendo", muy brillante que hablaba de su furor e impotencia ante la adversidad que los perseguía. (Marciano 1957: 71)
\end{abstract}

Al igual que podría ocurrir dentro de una obra literaria -tanto más en Bruja del Ávila, recibida por la crítica como sobredisciplinada y sobreadaptada-, la interpretación del pianista no orienta su pasión hacia la complacencia del público, sino a la expresión de una serie de emociones y deseos anegados en el pasado que se ha querido borrar. Lo que permite inferir que si bien los detentores del poder conservan, dentro de esta obra, la potestad de seleccionar ciertos espacios de la memoria útiles para la construcción de una identidad superviviente, la negociación con la Historia que lleva a cabo cada identidad puede seguir manteniendo entre sus límites las diferencias y contradicciones de este proceso de selección. Habría pues que singularizar cada expresión y cada trayectoria de vida para comprender la subjetividad que se expresa por medio de la interpretación musical y/o literaria.

En otras palabras, según lo aquí expuesto, se hallan algunas vías -aunque no demasiado conocidas, ni tan fáciles de transitar como las convencionales- para burlar la maquinaria de generación de identidades manejada por el Estado y, aunque existan varias posibilidades a este respecto, la mayoría de las opciones están asociadas al ejercicio de alguna práctica social indigerible desde el poder. Entonces, la búsqueda de nuevos lenguajes permitirá, por una parte, la evasiva de cualquier intento de codificación proveniente del Estado, al tiempo que instituirá el discurso como un territorio de resistencia.

En medio del juego de temporalidades, la interpretación musical ejecutada alternativamente por Francisca, el tío Fritz, Marina y el pianista judío contienen características singulares de cada uno de los espacios a donde pertenecen, pese a ello, también despliegan rasgos diacríticos que convierten a los ejecutantes en una comunidad. En el hecho simple de tocar piano -o de expresarse por medio de una voz poco distinguible en el mapa literario nacional- se trasluce una progresión de prescripciones rituales que convierten la carga política del discurso enunciado en expresiones semisagradas, imposibles de criminalizar. Ciertamente, se harán visibles algunos esfuerzos por espectacularizar las interpretaciones musicales hasta restarles cualquier valor reflexivo; no obstante, en las pequeñas tensiones que surjan dentro de su representación, se asomará la subjetividad indecible.

Por ejemplo, en el diálogo que sostienen Marina y Silvestre en torno al Piano de Chopin, esto se pone de manifiesto. En ese intercambio, la centralidad de Silvestre -casi diluida- y la autoproclamada marginalidad de Marina -también puesta bajo sospecha en ese instante-, van a dejar al descubierto dos formas de dialogar con el pasado y pensar el momento que habitan. Dos maneras de definir no sólo el espacio de pertenencia particular de cada uno, sino también la categoría de arraigo en sí misma. Silvestre afirma en este episodio:

\footnotetext{
-Yo he viajado, he contemplado todo lo que tú nombras, sin embargo nunca llegué a escuchar que el piano de Chopin llorara.

-Eso lo digo yo, ¿sabe la historia?

- No.

-Era una vez un músico famoso, ya había muerto Chopin, y como gracia especial, le propusieron tocar el piano que está en la Cartuja; allí fueron expertos y el artista, nadie lo había desde su muerte ni rozado, abrieron el teclado, luego la tapa grande y al contacto del primer acorde que dio el músico, con gran
} 
temor, despacio, lleno de reverencia, se rompieron las cuerdas una a una, hasta no quedar más que un informe mazo de metales rotos.

Silvestre comentó:

-Fue el contacto brusco del aire, las cuerdas tantos años oprimidas, envejecidas, mohosas, ¡era muy natural que así estallaran!

-No, así hablan los físicos, los que tienen el corazón sordo y no escuchan el alma que nos dice que, ¡hasta las cuerdas lloraron a aquel hombre! (Marciano 1957: 80-81)

En este texto, emerge un ir y venir del conocimiento histórico. Por un lado, Silvestre va de lo personal -es decir, de lo que atestiguó en el viaje- a lo social, en la misma medida en que Marina toma un acto público y lo inscribe en el espacio de lo privado. Ambos traslados ubicarán la Historia y la memoria en el territorio de la subjetividad y, aunque ninguno de ellos nutra al otro, los dos irán en paralelo, a partir de los niveles de centralidad del sujeto que los construya. A diferencia de lo que ocurría en la aproximación nacionalista a la Historia, tan en boga para la década de los cincuenta en Venezuela, en este caso, no habrá una individualidad resultante, sino muchas singularidades enunciadoras y diversas identidades emergentes, con más de una posibilidad de arraigo.

Precisamente, en este cruce que genera el "pasado social", Marciano inscribe a determinados sujetos sin voz ni rostro en las representaciones mediáticas y/o literarias de la Venezuela de la primera mitad del siglo XX. Lo que, además, explica porqué ha ejecutado este esfuerzo aparente de reconstrucción de un pasado anacrónico, de una concepción temporal que, desde su enunciado primero, se sabe fallido, pero que en su imperfección permite que se cuelen voces y percepciones humanizadoras de ciertos objetos materiales como un violín o, incluso, de algunas feminidades impensables como "la mujer espiritual".

Por otra parte, a diferencia de lo que ocurre con los textos editados en la primera mitad del siglo $\mathrm{XX}^{7}$, que intentaban reivindicar la memoria, en esta novela y, particularmente, en la reconstrucción de la leyenda de Chopin que se ha referido anteriormente, no se concibe la unidad discursiva como un fin posible, sino que - por el contrario- la autora se empeña en asentar que no existe una pieza de pasado con una ubicación fija, por tanto, cualquier orden que provenga de una experiencia individual, va a dejar como resultado una lectura de sentidos diversa e, inclusive, contradictoria, dependiente del sujeto reconstructor del episodio, más que de quienes lo protagonizaron.

Al respecto, vale la pena tener en cuenta que si, tal y como se proponía en el proyecto desarrollista, el discurso histórico constituía una plataforma útil para comprender -y no para producir- los sujetos y los movimientos sociales deseables para la nación, el pasado sería entonces un monumento incuestionable, imposible de revisar y de debatir. Es decir, la Historia constituiría un artefacto semejante cuerpo momificado que, al develarse en toda su literalidad dentro de Bruja del Ávila, desestabiliza y desorienta al sujeto letrado.

Ahora bien, cuando Marina lleva a Silvestre a "conocer" el cuerpo de su madre embalsamada, la autora señala cierta posibilidad interpretativa que acompaña a cada voz edificadora del pasado. Por ello, donde la mujer hermosa, sensual, extranjera y, en definitiva, rara percibe un objeto digno de adoración, su pareja ve una "cosa de locos", que no le remite a ningún significado cognoscible. El personaje masculino se confunde al percibir cómo la individualidad que lo acompaña, interroga la historia -descompuesta o petrificada-, la invita a intervenir el presente y le rinde cuentas de su conducta. Una puesta en escena que le atribuye a un acto lindante con lo siniestro, el mismo poder legitimador que se le atribuía a la rememoración en la década de los cincuenta. 
Este gesto desacralizador ante todas las formas instituidas en Occidente para reconstruir la memoria colectiva, se produce de manera franca. A partir de lo cual, las relaciones de la verdad con el discurso histórico son reescritas y la reflexión ante todas sus implicaciones proponen nuevas formas -fundamentadas en el caos- de evocación del pasado. O, usando otros términos, en Bruja del Ávila, se concreta un movimiento contrahistórico cuando se representa la muerte, un recurso agenciado como respuesta a la prospección temporal y como propuesta alternativa del ser. Con esta novela, Marciano recupera la fuerza fijadora subyacente a la construcción historiográfica y la lleva al extremo de lo grotesco.

\section{Notas}

1. En su texto El orden del discurso (2002), Michel Foucault asegura que: En una sociedad como la nuestra son bien conocidos los procedimientos de exclusión. El más evidente, y el más familiar también, es lo prohibido. Uno sabe que no tiene derecho a decirlo todo, que no se puede hablar de todo en cualquier circunstancia, que cualquiera, en fin, no puede hablar de cualquier cosa. Tabú del objeto, ritual de la circunstancia, derecho exclusivo o privilegiado del sujeto que habla: he ahí el juego de tres tipos de prohibiciones que se cruzan, refuerzan o se compensan, formando una compleja malla que no cesa de modificarse (Foucault 2002: 15). En el caso que nos ocupa, la malla ha sido completamente reestructurada, hecho que sugiere una alternativa de rememoración o, quizás, un replanteamiento del discurso histórico.

2. La referencia a Zizek y a Scott permite advertir, por ejemplo, la necesidad de adscripción genealógica evidenciada en la obra de Marciano, junto a la búsqueda de un referente pasado que legitime su expresión. Del mismo modo, puede ayudar a reconocer las razones diálogo que establece Bruja del Ávila con la Historia en tanto plataforma discursiva. Todo lo cual se produce más allá de que categorías como "género", "postestructuralismo" o "postfeminismo" no hayan podido ser empleadas para comprender la obra aquí estudiada.

3. En El sublime objeto de la ideología, Slavoj Zizek comenta: ¿Qué es lo que crea y sostiene la identidad de un terreno ideológico determinado más allá de todas las variaciones posibles de su contenido explícito? Hegemonía y estrategia socialista traza lo que tal vez sea la respuesta definitiva a esta pregunta crucial de la teoría de la ideología: el cúmulo de "significantes flotantes", de elementos postideológicos, se estructura en un campo unificado mediante la intervención de un determinado "punto nodal" (el point de caption lacaniano) que los "acolcha", detiene su deslizamiento y fija su significado. El espacio ideológico está hecho de elementos sin ligar, sin amarrar "significantes flotantes", cuya identidad está "abierta", sobredeterminada por la articulación de los mismos en una cadena con otros elementos -es decir, su significación "literal" depende de su plus de significación metafórico (Zizek 2001: 125). La propuesta de Scott estaría fundamentada, entonces, en detener el flujo de los significantes ideológicos a partir de la categoría de "género" y, con ello, tejer una red de significados -historia, origen, pertenencia, memoria, etc.- con una totalización alternativa.

4. En su libro Acto de presencia, Sylvia Molloy refiere detenidamente la importancia de "la escena de la lectura" dentro de los textos autobiográficos. Aún más, al hablar del uso que le da a este tópico Victoria Ocampo, señala que: se ve a sí misma representando: lleva el libro (como un actor que entra en escena llevando un objeto de utilería) y finge leer. La escena recalca tanto la distancia como la familiaridad: la niña lleva un libro lleno de letras a las que no tiene acceso, pero es un libro cuyo contenido le es del todo conocido porque se lo han leído innumerables veces (Molloy 1996: 79). Posteriormente añade que: La simulación de Ocampo con el libro en la mano, aunque claramente imitativa, difiere de la de Sartre en que Ocampo no tiene a su alrededor un lector paradigmático, ya sea "seriamente" masculino o "frívolamente" femenino, sobre el cual modelar su propia lectura. Ninguno de los adultos presentes 
en su niñez está asociado con los libros de manera ejemplar (Molloy 1996: 80). En la obra de Marciano, la recuperación de este episodio adquiere algunos sentidos nuevos. Por ejemplo, cuando Silvestre se encuentra apartado de todos, sustituye la simulación por una lectura "real", que le permite contaminarse de sentidos plurales; del mismo modo, si bien imita la forma de lectura de Dolorita, el contenido y el resultado del contacto con el libro va a ser otro; finalmente, el resultado que queda de este rito iniciático es un hombre enamorado, capaz de racionalizar sus afectos. Por tanto, más que erigirse en condición de sujeto biográfico por excelencia, se acerca al estereotipo de las mujeres sin "vida contable" que se ve resignado a construir.

5. Sin duda, la figura del intérprete de piano constituye un elemento recurrente en Bruja del Ávila y establece una familia de personajes que, de ninguna otra forma, hubiera podido pensarse como colectivo. En primer lugar, aparece una mujer que pretende a Silvestre, pero que él no considera atractiva, pues entre otras cosas- toca el piano según las directrices de su maestro; en segundo término, se señala al tío Fritz, uno de los constructores del pensamiento universal, pese a las debilidades humanas que presenta en su constitución o, lo que es lo mismo, una figura alternativa del intelectual formador; luego, aparece Marina, quien es capaz de desencadenar una reconstrucción del pasado cuando se expresa por medio de la música; y, finalmente, se construye un personaje que toca para sobrevivir. Al igual que cualquier otra elaboración discursiva -o, incluso, podría decirse que literaria- los diferentes usos que se le da a la música dentro de este texto perfilan diversos sujetos-autores, cuya presencia en el campo intelectual venezolano es reclamada por la voz narrativa.

6. Aunque se trate de una historia poco difundida para la fecha de publicación de Bruja del Ávila (1957), este episodio, Alecia Marciano pareciera referir El pianista del gueto de Varsovia, de Vladislaw Szpliman, un libro escrito en 1946, pero censurado de inmediato y durante años en Europa. El texto fue reeditado y adaptado para el cine en la década de los noventa del siglo XX y cuenta la historia de un pianista que durante la invasión Nazi a Polonia, se dedica a tocar para los líderes del nacionalsocialismo y, por eso, consigue evadir su ejecución. Evidentemente, no es fácil de demostrar la referencia directa por parte de la autora; no obstante, en caso de haber existido, reforzaría el marcaje territorial entre alta y baja cultura, y entre la mujer esencial y la voz real que se ha referido anteriormente.

7. Aunque sobrarían los ejemplos de textos venezolanos que tratan de negociar el proyecto nacional en curso con el pasado, en este caso particular, la referencia está dirigida a aquellos que desplazan el saber positivista de la Historia por el ejercicio de rememoración tan "incuestionable" como el primero. Textos como Sol interior (1918) o Cubagua (1931), de Enrique Bernardo Núñez; Memorias de un venezolano de la decadencia (1937), de José Rafael Pocaterra; Fiebre (1938), de Miguel Otero Silva; e, inclusive, Cantaclaro (1934), de Rómulo Gallegos.

\section{Bibliografía}

Foucault, Michel. 1984. “¿Qué es un autor?”. Dialéctica. 9 (16): 51- 83.

2002. El orden del discurso. Buenos Aires: Tusquets editores.

Lamas, Marita (comp.). 2000. El género. La construcción cultural de la diferencia sexual. México D.F: Programa Universitario de Estudios de Género. Universidad Nacional Autónoma de México.

Luna, Lola. 1996. Leyendo como mujer la imagen de la mujer. Barcelona: Anthropos. 
Mancera Galletti, Ángel. 1958. ¿Quiénes narran y cuentan en Venezuela? Caracas- México D.F: Ediciones Caribe.

Marciano, Alecia. 1957. Bruja del Ávila. México D.F: Gráfica Panamericana.

Molloy, Sylvia. 1996. Acto de presencia. México D.F.: Fondo de Cultura Económica.

Pantin, Yolanda y Torres, Ana Teresa (eds.). 2003. El hilo de la voz. Antología crítica de escritoras venezolanas. Caracas: Angria ediciones.

Pla y Beltrán, P. 1958. “Las coquetas”. Revista Nacional de Cultura, 127 (20): 175-176.

Scott, Joan W. 2000. El género: una categoría útil para el análisis histórico. En: Lamas (comp.), 265-302.

Zizek, Slavoj. 2001. El sublime objeto de la ideología. Siglo XXI editores, México D.F. 